Goldschmidt 2021 Abstract

https://doi.org/10.7185/gold2021.7112

\section{Peatlands as patchworks of water- rock and water-peat interactions: The case study of the Frasne peatland, Jura Mountains, France.}

ALEXANDRE LHOSMOT ${ }^{1}$, MARC STEINMANN ${ }^{1}$, JEAN SÉBASTIEN MOQUET $^{2}$, LAURE GANDOIS ${ }^{3}$, PHILIPPE BINET $^{1}$, VANESSA STEFANI ${ }^{1}$, ANNE BOETCH ${ }^{1}$, MARIELAURE TOUSSAINT $^{1}$ AND GUILLAUME BERTRAND ${ }^{1}$

${ }^{1}$ University of Bourgogne Franche-Comté, UMR UFC CNRS 6249 Chrono-Environnement

${ }^{2}$ Institut des Sciences de la Terre d'Orléans (ISTO), UMR7327

${ }^{3}$ EcoLab, Université de Toulouse, CNRS

Presenting Author: alexandre.lhosmot@univ-fcomte.fr

Although peatlands occupy only $3 \%$ of the global continental surface, they constitute a Critical Zone's outstanding compartment. They provide socio-ecosystemic services such as water and hydrochemical regulation, carbon storage and biodiversity conservation. These latter depend directly on the complex interaction between chemical-water fluxes, vegetation cover, and carbon exchange dynamics.

Fluvial carbon exports are critical for establishing peatland carbon budgets. In order to evaluate the origin (organic matter mineralization and/or weathering) of inorganic carbon exported from peatlands, we studied the Frasne peatland (French Jura Mountains; 46.826 N, 6.1754 E; $850 \mathrm{~m}$ a.s.l), located in a karstified syncline overlain by fluvio-glacial deposits. Rainwater, porewater and outflow waters are sampled monthly since October 2019 and analyzed for physico-chemical parameters ( $\mathrm{T}$, Eh, $\mathrm{pH}$, electrical conductivity), major elements, DOC, DIC and isotopic signatures $\left(\delta^{18} \mathrm{O}_{\mathrm{H} 2 \mathrm{O}}, \delta^{2} \mathrm{H}_{\mathrm{H} 2 \mathrm{O}}, \delta^{13} \mathrm{C}_{\mathrm{DIC}}\right)$.

Preliminary results show that outflow water presents signature close to recent local rainfall $\left(\delta^{18} \mathrm{O}=-7.6 \%\right.$ VSMOW; $\delta^{2} \mathrm{H}=-50$ $\%$ VSMOW) suggesting a direct link between local inputs and outflow during high Water Level Period (WLP). In contrast, pore water signatures highlight a 3D heterogeneity of water supplies. Enriched values suggest local origin whereas depleted signatures could be consistent with recharge in altitude over local mountains. Temporal monitoring will refine water supply processes at different WLP.

Regarding DIC origin, greater $\mathrm{HCO}_{3}$ values are usually associated with the most depleted $\delta^{18} \mathrm{O}$ and higher $\delta^{13} \mathrm{C}$ (about $-15 \%$ v-PDB) calculated for open $\mathrm{CO}_{2}$ conditions, suggesting contributions from regional karstic groundwaters (Fig. 1A-B-D). In contrast low alkalinity waters present lower $\delta^{13} \mathrm{C}(-22 \%$ vPDB) consistent with dominant biogenic contributions.

Hence, various degree of water-rock (greater $\mathrm{HCO}_{3}$ and $\delta^{13} \mathrm{C}$ ) or water-peat (greater DOC, DIC, and lower $\delta^{13} \mathrm{C}$ ) interaction (Figure 1) degrees appear preferentially associated with specific water origins (distant/local) and specific water transfer across the peatland then transferred to the outlet in a complex way. This raises questions about hydrogeochemical response of midlatitude peatlands acting as a mosaic-like geochemical system (Figure 2), to hydrological alterations predicted for the future decades. Then, it could modify the peatland's role for inorganic and organic carbon transfers at the watershed scales.
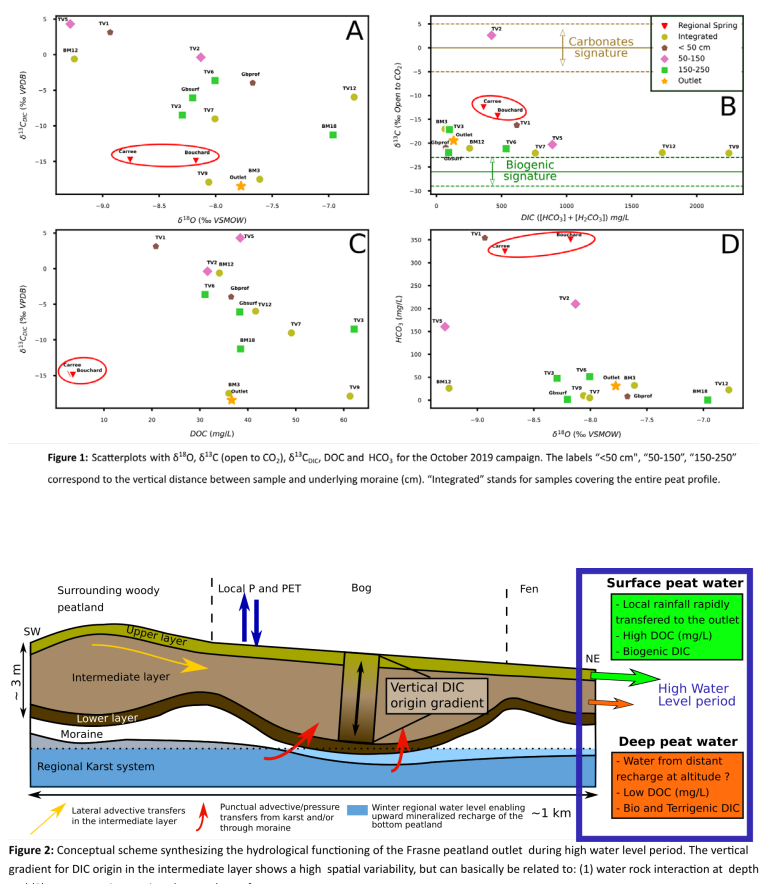

gradient for DiC origi in the intermediate layer shows.
and (2) water peat interaction close to the surface. 